\title{
The first consecutive 5000 patients with Coronavirus Disease 2019 from Qatar; a nation-wide cohort study
}

Ali S. Omrani ${ }^{*}$ (D), Muna A. Almaslamani ${ }^{1}$, Joanne Daghfal ${ }^{1}$, Rand A. Alattar ${ }^{1}$, Mohamed Elgara $^{2}$, Shahd H. Shaar ${ }^{1}$, Tawheeda B. H. Ibrahim', Ahmed Zaqout', Dana Bakdach³, Abdelrauof M. Akkari ${ }^{3}$, Anas Baiou ${ }^{3}$, Bassem Alhariri ${ }^{4}$, Reem Elajez ${ }^{5}$, Ahmed A. M. Husain ${ }^{1}$, Mohamed N. Badawi ${ }^{1}$, Fatma Ben Abid', Sulieman H. Abu Jarir ${ }^{1}$, Shiema Abdalla ${ }^{1}$, Anvar Kaleeckal ${ }^{6}$, Kris Choda ${ }^{6}$, Venkateswara R. Chinta ${ }^{6}$, Mohamed A. Sherbash $^{7}$, Khalil Al-Ismail ${ }^{1}$, Mohammed Abukhattab ${ }^{1}$, Ali Ait Hssain ${ }^{3}$, Peter V. Coyle ${ }^{8}$, Roberto Bertollini ${ }^{9}$, Michael P. Frenneaux ${ }^{10}$, Abdullatif Alkhal ${ }^{1}$ and Hanan M. Al-Kuwari ${ }^{9}$

\section{Abstract}

Background: There are limited data on Coronavirus Disease 2019 (COVID-19) outcomes at a national level, and none after 60 days of follow up. The aim of this study was to describe national, 60-day all-cause mortality associated with COVID-19, and to identify risk factors associated with admission to an intensive care unit (ICU).

Methods: This was a retrospective cohort study including the first consecutive 5000 patients with COVID-19 in Qatar who completed 60 days of follow up by June 17, 2020. The primary outcome was all-cause mortality at 60 days after COVID-19 diagnosis. In addition, we explored risk factors for admission to ICU.

Results: Included patients were diagnosed with COVID-19 between February 28 and April 17, 2020. The majority (4436, 88.7\%) were males and the median age was 35 years [interquartile range (IQR) 28-43]. By 60 days after COVID-19 diagnosis, 14 patients (0.28\%) had died, 10 (0.2\%) were still in hospital, and two (0.04\%) were still in ICU. Fatal COVID-19 cases had a median age of 59.5 years (IQR 55.8-68), and were mostly males (13, 92.9\%). All included pregnant women $(26,0.5 \%)$, children $(131,2.6 \%)$, and healthcare workers $(135,2.7 \%)$ were alive and not hospitalized at the end of follow up.

A total of 1424 patients (28.5\%) required hospitalization, out of which 108 (7.6\%) were admitted to ICU. Most frequent co-morbidities in hospitalized adults were diabetes (23.2\%), and hypertension (20.7\%). Multivariable logistic regression showed that older age [adjusted odds ratio (aOR) 1.041, 95\% confidence interval (Cl) 1.022-1.061 per year increase; $P<0.001$ ], male sex (aOR 4.375, 95\% Cl 1.964-9.744; $P<0.001$ ), diabetes (aOR 1.698, 95\% Cl 1.0502.746; P 0.031), chronic kidney disease (aOR 3.590, 95\% Cl 1.596-8.079, P 0.002), and higher BMI (aOR 1.067, 95\% Cl 1.027-1.108 per unit increase; P 0.001), were all independently associated with increased risk of ICU admission.

(Continued on next page)

\footnotetext{
*Correspondence: aomrani@hamad.qa

${ }^{1}$ Communicable Diseases Center, Hamad Medical Corporation, Doha, QatarPO Box 3050

Full list of author information is available at the end of the article
}

(c) The Author(s). 2020 Open Access This article is licensed under a Creative Commons Attribution 4.0 International License, which permits use, sharing, adaptation, distribution and reproduction in any medium or format, as long as you give appropriate credit to the original author(s) and the source, provide a link to the Creative Commons licence, and indicate if changes were made. The images or other third party material in this article are included in the article's Creative Commons licence, unless indicated otherwise in a credit line to the material. If material is not included in the article's Creative Commons licence and your intended use is not permitted by statutory regulation or exceeds the permitted use, you will need to obtain permission directly from the copyright holder. To view a copy of this licence, visit http://creativecommons.org/licenses/by/4.0/ The Creative Commons Public Domain Dedication waiver (http://creativecommons.org/publicdomain/zero/1.0/) applies to the data made available in this article, unless otherwise stated in a credit line to the data. 
(Continued from previous page)

Conclusions: In a relatively younger national cohort with a low co-morbidity burden, COVID-19 was associated with low all-cause mortality. Independent risk factors for ICU admission included older age, male sex, higher BMI, and co-existing diabetes or chronic kidney disease.

Keywords: Coronavirus, COVID-19, SARS-CoV-2, Mortality, Qatar

\section{Background}

Severe Acute Respiratory Syndrome Coronavirus 2 (SARS-CoV-2), the cause of Coronavirus Disease 2019 (COVID-19), emerged in China in late 2019. By July 12, 2020, more than 12 million confirmed SARS-CoV-2 infections were confirmed worldwide, with over 500 thousand associated deaths [1].

Based on the number of deaths as a proportion of reported COVID-19 cases, the overall estimated COVID-19-associated mortality rate is around 5.7\% [2]. However, the accuracy of such a figure is uncertain given the variation in case finding policies from one healthcare setting to another $[3,4]$. Furthermore, reported mortality has been mostly based on in-hospital outcomes or relatively short follow up [5-9]. In their recently published recommendations for a minimal common outcome measure set for COVID-19 research, the World Health Organization (WHO) favored that mortality outcomes are assessed at 60 days [10].

Single and multi-center cohort studies suggested that risk factors for severe COVID-19 include male sex, older age, and the presence of multiple comorbidities [7, 9, 11]. The extent to which such risk factors are important at a population level in settings with ample healthcare resources, a COVID-19 control program based on active case finding and isolation, and a low burden of comorbidities, is unknown.

In this study, we describe 60-day outcomes of a nationwide COVID-19 cohort from Qatar, and explore patient characteristics associated with the need for admission to an intensive care unit (ICU).

\section{Methods}

\section{Study setting}

Hamad Medical Corporation (HMC) encompasses multiple hospital facilities and provides all COVID-19 medical care for the 2.8 million population of Qatar. In response to the COVID-19 pandemic, existing clinical services were re-organized and two brand new hospital facilities were opened ahead of their originally planned dates. In total, non-ICU bed capacity was increased from 2143 to 3469 (61.9\% increase), and ICU beds from 130 to 529 (306.9\% increase). From a healthcare delivery perspective, HMC defines adults as those aged above 14 years.
SARS-CoV-2 infection was diagnosed by real-time polymerase chain reaction (RT-PCR) assays TaqPath COVID-19 Combo Kit (Thermo Fisher Scientific, Waltham, Massachusetts) or Cobas SARS-CoV-2 Test (Roche Diagnostics, Rotkreuz, Switzerland) on respiratory tract specimens. Severity of COVID-19 was classified according to the WHO guidelines [11]. SARS-CoV2 testing was offered to all individuals presenting with symptoms suggestive of COVID-19, known close contacts of confirmed cases including healthcare workers, and all returning travelers.

Patients with asymptomatic SARS-CoV-2 infection or mild COVID-19 without significant co-morbidities were isolated in dedicated community facilities until they had two consecutive negative SARS-CoV-2 RT-PCR results from upper airway samples taken more than $24 \mathrm{~h}$ apart. COVID-19 patients with significant co-morbidities or moderate to severe disease were hospitalized for inpatient management. Standard care for hospitalized patients involved supportive care and investigational antiviral therapy. Individual regimens were selected by the treating physicians based on severity of disease, the presence of contra-indications or potential drug-drug interactions, and the patients' preferences. Twenty five individuals included in this study had been elsewhere reported [12].

\section{Procedures}

We used the HMC COVID-19 database to identify the first consecutive 5000 patients with RT-PCR-confirmed COVID-19 who would complete 60 days of follow up from date of diagnosis by June 17, 2020. During the period between May 24 and June 18, 2020, clinical and laboratory data were retrieved from HMC's electronic healthcare system. Final status 60 days after COVID-19 diagnosis was ascertained against the electronic healthcare system and Qatar's national deaths records.

The report was prepared according the Strengthening the Reporting of Observational Studies in Epidemiology (STROBE) recommendations [13].

\section{Outcomes}

The primary endpoint was all-cause mortality within 60 days after RT-PCR confirmation of SARS-CoV-2 
infection. For hospitalized patients, we also assessed risk factors for admission to ICU.

\section{Statistical analysis}

We summarized categorical data as numbers and percentages and compared them using Pearson's chisquared or Fisher's exact test, as appropriate. Continuous data are presented as medians and interquartile ranges (IQR) and compared among groups using Wilcoxon rank-sum test. The majority ( 82 patients, $75.2 \%$ ) of admissions to ICU occurred within of the first $48 \mathrm{~h}$ from hospitalization. We therefore used logistic regression to explore predictors of admission to ICU.

Baseline variables were included in the univariable logistic regression analysis if their between groups differences were associated with $P$ values of $<0.05$. Independent variables in the multivariable regression model were chosen based on their association with $P$ values of $<0.1$ in the univariable logistic regression, and on their ready availability before any COVID-19-related clinical evaluation. Due to the number of events in the study, we limited the number of independent variables in the multivariable regression analysis to eight to avoid overfitting the model. The final multivariable logistic regression model included age, male sex, body mass index (BMI), defined as body weight in kilograms divided by squared height in meters, and co-existing diabetes mellitus, systemic hypertension, coronary artery disease, chronic liver disease, and chronic kidney disease. Multiple imputations approach was applied for variables with $>5 \%$ missingness.

All $P$ values were two-sided with a threshold of $<0.05$ for statistical significance. Statistical analyses were performed using Stata Statistical Software Release 15.1 (StataCorp LLC, College Station, Texas).

\section{Results}

Individuals included in this study were diagnosed with SARS-CoV-2 infection between February 28 and April 17, 2020. Initial SARS-CoV-2 cases were diagnosed in travelers returning from Iran and Europe. Sustained local transmission became established thereafter (Fig. 1). Of the 5000 RT-PCR-confirmed COVID-19 cases included in this report, $4436(88.7 \%)$ were in males and the majority belonged to age groups $25-34$ years (1811, $36.2 \%)$ and $35-44$ years $(1445,28.9 \%)$ (Fig. 2). The cohort included $131(2.6 \%)$ individuals aged 14 years or less, $26(0.5 \%)$ pregnant women and 135 (2.7\%) healthcare workers (Table S1, appendix).

Most individuals in this study did not require hospitalization $(3576,71.5 \%)$. Those who were not hospitalized were significantly younger and had fewer co-existing chronic medical conditions (Table S1, appendix). Of 1424 patients who required hospitalization, 108
(7.6\%) were admitted to ICU. Overall, 60 days after COVID-19 diagnosis, 14 patients $(0.28 \%)$ had died, 10 patients $(0.2 \%)$ were still in hospital and two (0.04\%) were still in ICU (Fig. 3).

\section{Hospitalized adults}

Out of 4869 individuals aged $>14$ included in this report, 1409 (28.9\%) were hospitalized. The majority (1167, 82.8\%) were males and the median age was 39 years (IQR 30-50). Nationalities from WHO's SouthEast Asia Region (791, 56.1\%) and Eastern Mediterranean Region $(485,34.4 \%)$ were most frequent. Diabetes (327, 23.2\%) and hypertension $(292,20.7 \%)$ were the most common co-existing medical conditions. Fever (58.3\%) and cough (59.1\%) were the most common presenting symptoms. Median BMI was $26.8 \mathrm{~kg} / \mathrm{m}^{2}$ (IQR 23.9-29.8). Most patients (1233, 87.5\%) did not require oxygen therapy within the first $24 \mathrm{~h}$ of hospitalization. Hydroxychloroquine (1044, 74.1\%), azithromycin (898, $63.7 \%)$, and lopinavir-ritonavir (522, 37\%) were the most commonly used investigational antiviral agents.

Compared with those who did not require ICU admission, ICU patients were significantly more likely to be males $(P \quad 0.005)$, have higher median age $(P<0.001)$ and to have multiple co-morbidities $(P<0.001)$ (Table 1$)$. They also had significantly higher median BMI (28.2 versus 26.6, $P<0.001)$ and were more likely to present with fever, cough and dyspnea $(P<0.001$ for each). Within the first $24 \mathrm{~h}$ of hospitalization, ICU patients had significantly higher median heart rate ( 95 versus 86 per minute, $P<0.001)$, and respiratory rate $(26.5$ versus 19 per minute, $P<0.001)$, significantly lower oxygen saturation (94\% versus 98\%, $P<0.001$ ) (Table 1 ). In addition, baseline blood investigations from ICU patient were significantly more likely to show lower median peripheral lymphocyte count $\left(1.0\right.$ versus $\left.1.7 \times 10^{9} / \mathrm{L}, P<0.001\right)$, and higher median serum creatinine (90 versus $80 \mu \mathrm{mol} /$ L, $P<0.001)$, and $C$-reactive protein $(\mathrm{CRP})(107.7$ versus $7, P<0.001)$. Complications such as acute kidney injury (43.5\% versus $1.5 \%)$, and myocardial injury (14.8\% versus $0.3 \%, P<0.001)$ were more common in ICU compared with non-ICU patients. Other baseline characteristics, management, and complications variables in hospitalized COVID-19 adults included in this study are shown in Table 1.

\section{Risk factors for ICU admission}

In univariable analysis, the odds of admission to ICU were significantly higher in older patients, males compared with females, and in those with diabetes, hypertension, coronary artery disease, or chronic lung, liver, or kidney disease, and in those with higher BMI (Table 2). The presence of cough, dyspnea, or fever, elevated baseline heart rate or respiratory rate, decreased 


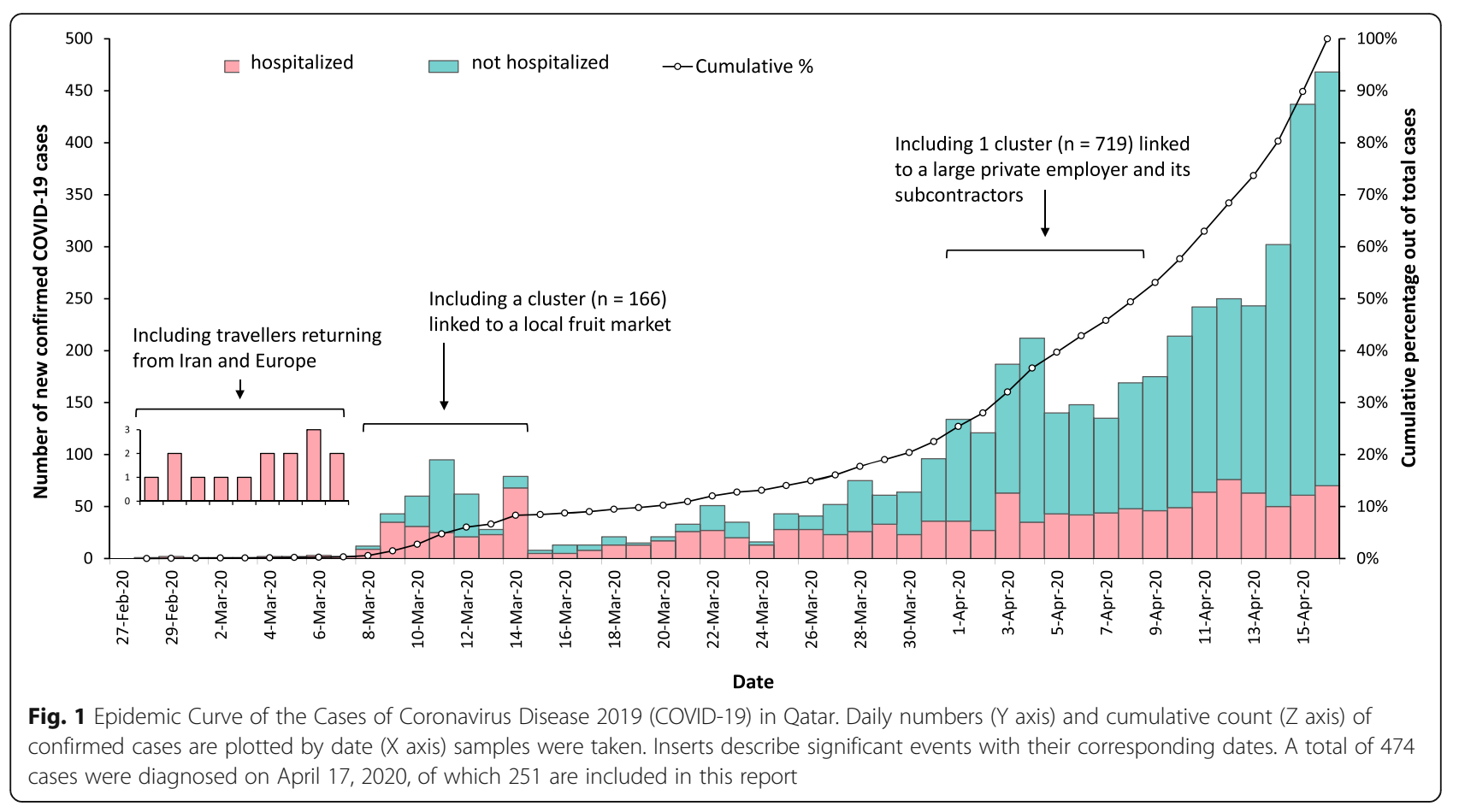

oxygen saturation, lower lymphocyte count, and increased serum creatinine, CRP, and alanine transaminase (ALT) were also associated with admission to ICU (Table 2).

In the multivariable logistic regression, we found that older age, male sex, co-existing diabetes or chronic kidney disease, and higher BMI were all independently associated with increased risk of need for ICU admission (Table 2).

\section{Fatal COVID-19}

A total of 14 patients $(0.28 \%$ ) died within 60 days of follow up. The median age of fatal COVID-19 cases was 59.5 years (IQR 55.8-68). Most deceased patients were males $(13,92.9 \%)$ and most $(8,57.1 \%)$ had two or more comorbidities (see Table S2 in Supplementary Material).

Two patients died without hospitalization. The first was a 59-year-old man with a history of hypertension and heavy smoking. He had asymptomatic SARS-CoV-2 infection and was isolated in a community facility pending viral clearance. He developed severe chest pain and cardiopulmonary arrest 17 days after COVID-19 diagnosis. The second patient was a 74-year-old man with end-stage kidney disease, hypertension, diabetes and coronary artery disease. He developed cardiopulmonary arrest shortly after presenting to the emergency department in severe respiratory distress. A post-mortem examination to confirm the cause of death was not performed in either case.

The remaining 12 deaths all occurred in patients who were in ICU with severe acute respiratory distress syndrome requiring prolonged invasive mechanical ventilation. Deaths occurred after a median of 24 days (IQR 14-49) from COVID-19 diagnosis. Ten (86.5\%) deaths occurred in patients aged 55 or older. The remaining two were in patients aged 54 years and 24 years. The former had diabetes, hypertension, and obesity (BMI 38.7). The latter patient presented with fulminant hepatitis and his hepatitis B serology was positive for surface IgM antibodies. He died within 11 days with encephalopathy and multi-organ failure.

\section{Pregnant women with SARS-CoV-2 infection}

The study included 26 pregnant women with SARSCoV-2 infection with median age of 29 years (IQR 25.5$33)$. Nineteen $(73.1 \%)$ were hospitalized, including one (3.8\%) in ICU, and all were discharged within the follow up period. Ten (38.5\%) pregnant women with COVID19 gave birth during the follow up period; all resulting in healthy babies with negative SARS-CoV-2 tests (see Table S3 in Supplementary Material).

\section{Healthcare workers with SARS-CoV-2 infection}

A total of 135 patients in this cohort were healthcare workers. Their median age was 35 years (28-43) and the majority were males $(101,74.8 \%)$. The most frequent professional background of affected healthcare workers was nursing $(49,36.3 \%)$, and allied healthcare $(27,20 \%)$ (see Table S4 in Supplementary Material). Out of 63 (46.6\%) who required hospitalization, three $(2.2 \%)$ required admission to ICU. All healthcare workers in this 


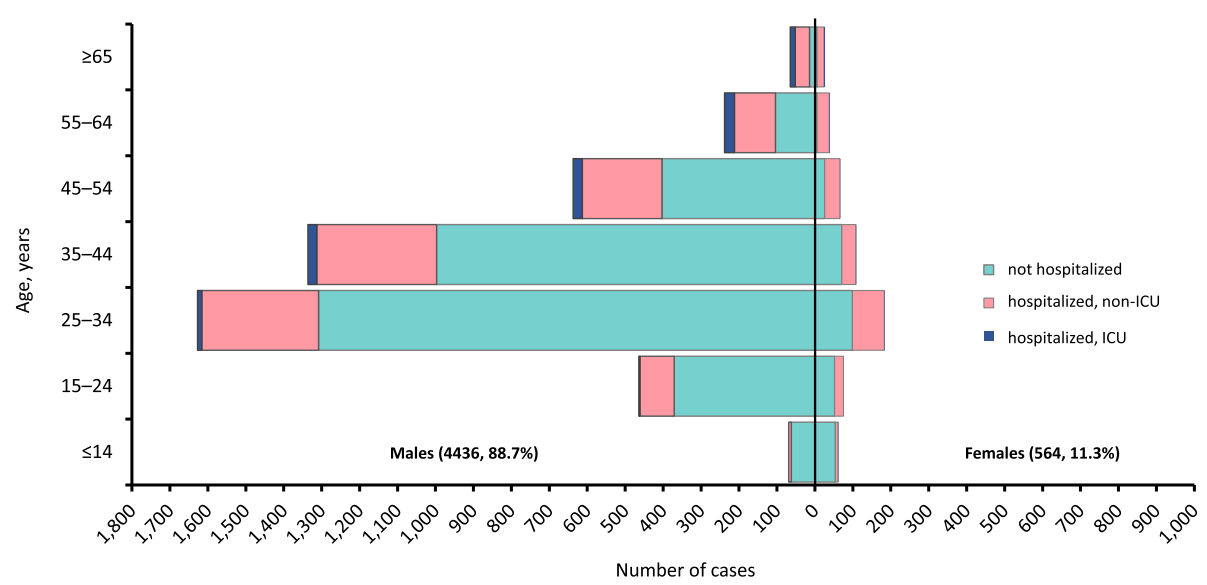

Fig. 2 Patients with Coronavirus Disease 2019 (COVID-19) Stratified by Age Group and Sex. X axis, numbers by sex; Y axis age group (years)

study were alive and out of hospital at end of follow up (see Table S4 in Supplementary Material).

\section{Children with SARS-CoV-2 infection}

There were 131 individuals aged 14 years or less in the study, of which $69(52.7 \%)$ were males. Median age was 7 years (IQR 4-10). Children were mostly diagnosed in the context of contact screening $(75 / 123,61 \%)$, and were not hospitalized (116, 88.5\%). The majority (120, 91.6\%) of children, including all seven infants, had family members with confirmed COVID-19 (see Table S5 in Supplementary Material).

\section{Discussion}

In this national COVID-19 cohort, only $14(0.28 \%)$ out of 5000 patients died within 60 days of diagnosis, and 12
$(0.24 \%)$ required ongoing hospitalization at the end of the 60-day follow up period.

SARS-CoV-2 infection are generally slightly more common in males than females [14]. However Our report shows that $88.7 \%$ of SARS-CoV-2 infections in Qatar were in males. Our findings reflect the country's demographic characteristics. Male to female ratio in Qatar's general population is 2.8 and the corresponding male to female SARS-CoV-2 incidence per 100,000 population in our report is 2.1. Notably, the population's male to female ratios are 3.5-3.7 in age groups between 25 to $54(3.5-3.7)$, where $68.9 \%$ of SARS-CoV-2 infections where reported (Table S6, supplement).

Our mortality rates are considerably lower than previously reported form large COVID-19 cohorts from China, Europe and United States [5-9]. There are

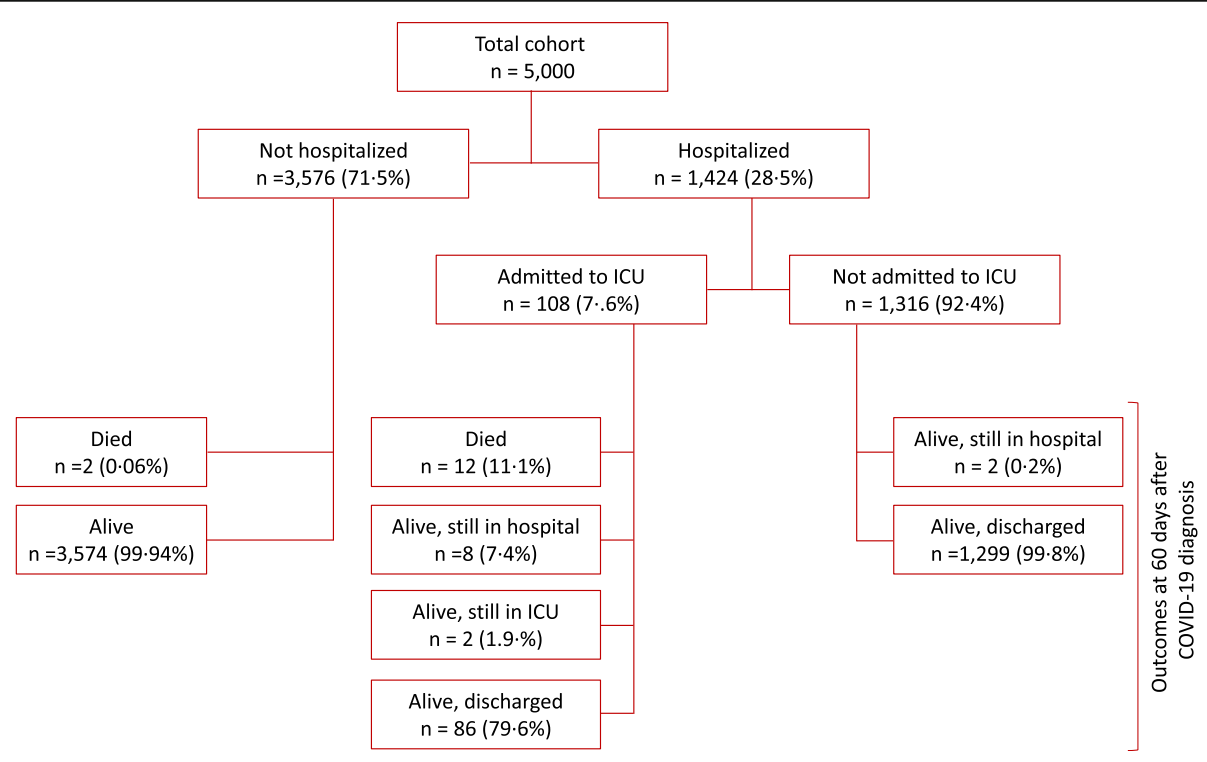

Fig. 3 60-Day Outcomes of Patients with Coronavirus Disease 2019 (COVID-19) 
Table 1 Baseline characteristics, management and complications in adults hospitalized with Coronavirus Disease 2019 in Qatar

\begin{tabular}{|c|c|c|c|}
\hline Variable & Non-ICU $(n=1301)$ & ICU $(n=108)$ & $P$ value \\
\hline \multicolumn{4}{|l|}{ Baseline characteristics } \\
\hline Male sex & 1067 (82\%) & $100(92.6 \%)$ & 0.005 \\
\hline Age (years) & $38(30-49)$ & $49.5(39.5-60)$ & $<0.001$ \\
\hline Age group (years) & & & $<0.001$ \\
\hline $15-24$ & $113(8.7 \%)$ & $3(2.8 \%)$ & \\
\hline $25-34$ & $391(30.1 \%)$ & $12(11.1 \%)$ & \\
\hline $35-44$ & $353(27.1 \%)$ & $24(22.2 \%)$ & \\
\hline $45-54$ & $250(19.2 \%)$ & $25(23.1 \%)$ & \\
\hline $55-64$ & $138(10.6 \%)$ & $28(25.9 \%)$ & \\
\hline$\geq 65$ & $56(4.3 \%)$ & $16(14.8 \%)$ & \\
\hline Nationality according to WHO region & & & 0.005 \\
\hline African Region & $27(2.1 \%)$ & $2(1.9 \%)$ & \\
\hline Eastern Mediterranean Region & $449(34.5 \%)$ & $36(33.3 \%)$ & \\
\hline European Region & $22(1.7 \%)$ & $2(1.9 \%)$ & \\
\hline Region of the Americas & $11(0.8 \%)$ & $2(1.9 \%)$ & \\
\hline South-East Asia Region & 739 (56.8\%) & $52(48.1 \%)$ & \\
\hline Western Pacific Region & $53(4.1 \%)$ & $14(13 \%)$ & \\
\hline Healthcare workers & $60(4.6 \%)$ & $3(2.8 \%)$ & 0.48 \\
\hline Pregnant & $18(1.4 \%)$ & $1(0.9 \%)$ & 1.0 \\
\hline Diabetes mellitus & 275 (21.1\%) & $52(48.1 \%)$ & $<0.001$ \\
\hline Hypertension & $248(19.1 \%)$ & $52(48.1 \%)$ & $<0.001$ \\
\hline Coronary artery disease & $31(2.4 \%)$ & $10(9.3 \%)$ & $<0.001$ \\
\hline Chronic lung disease & $73(5.6 \%)$ & $10(9.3 \%)$ & 0.12 \\
\hline Chronic liver disease & $14(1.1 \%)$ & $4(3.7 \%)$ & 0.043 \\
\hline Chronic kidney disease & $21(1.6 \%)$ & $13(12 \%)$ & $<0.001$ \\
\hline Malignancy & $18(1.4 \%)$ & $2(1.9 \%)$ & 0.66 \\
\hline Number of comorbidities & & & $<0.001$ \\
\hline None & $859(66.0 \%)$ & $35(32.4 \%)$ & \\
\hline One comorbidity & $268(20.6 \%)$ & $33(30.6 \%)$ & \\
\hline Two comorbidities & $124(9.5 \%)$ & $20(18.5 \%)$ & \\
\hline More than two comorbidities & $50(3.8 \%)$ & $20(18.5 \%)$ & \\
\hline Current or past smoker & $121 / 806(15 \%)$ & 9/52 (17.3\%) & 0.71 \\
\hline Mode of presentation & & & $<0.001$ \\
\hline Screening or contact tracing & 390/1293 (30.2\%) & 0 & \\
\hline Symptomatic & 903/1293 (69.8\%) & $108(100 \%)$ & \\
\hline \multicolumn{4}{|l|}{ Symptoms } \\
\hline Fever & $710 / 1289(55.1 \%)$ & $105(97.2 \%)$ & $<0.001$ \\
\hline Cough & $730 / 1289(56.6 \%)$ & $97(89.8 \%)$ & $<0.001$ \\
\hline Sore throat & $345 / 1289(26.8 \%)$ & $21(19.4 \%)$ & 0.11 \\
\hline Rhinorrhea & 130/1289 (10.1\%) & $1(0.9 \%)$ & $<0.001$ \\
\hline Dyspnea & $156 / 1289(12.1 \%)$ & $56(51.9 \%)$ & $<0.001$ \\
\hline Fatigue & $121 / 1289(9.4 \%)$ & $15(13.9 \%)$ & 0.13 \\
\hline Generalized pain & 265/1289 (19.9\%) & $21(19.4 \%)$ & 0.9 \\
\hline Diarrhea & $53 / 1289(4.1 \%)$ & $2(1.9 \%)$ & 0.43 \\
\hline Nausea and/or vomiting & $52 / 1289(4.0 \%)$ & $10(9.3 \%)$ & 0.024 \\
\hline \multicolumn{4}{|c|}{ Measurements, vital signs, and laboratory results within the first $24 \mathrm{~h}$ of hospitalization } \\
\hline Body mass index $\left(\mathrm{kg} / \mathrm{m}^{2}\right)$ & $26.6(23.8-29.7)$ & $28.2(25.8-31.6)$ & $<0.001$ \\
\hline Systolic blood pressure ${ }^{\dagger}(\mathrm{mmHg})$ & $117.0(108-127)$ & $116(103.5-126)$ & 0.074 \\
\hline
\end{tabular}


Table 1 Baseline characteristics, management and complications in adults hospitalized with Coronavirus Disease 2019 in Qatar (Continued)

\begin{tabular}{|c|c|c|c|}
\hline Variable & Non-ICU $(n=1301)$ & ICU $(n=108)$ & $P$ value \\
\hline Temperature $^{\mathrm{b}}\left({ }^{\circ} \mathrm{C}\right)$ & $37.0(36.8-37.9)$ & $37.8(37.1-38.7)$ & $<0.001$ \\
\hline Hear rate ${ }^{c}$ (beats per minute) & $86(78-97)$ & $95(86-108)$ & $<0.001$ \\
\hline Respiratory rate ${ }^{d}$ (breaths per minute) & $19(18-20)$ & $26.5(20-32.5)$ & $<0.001$ \\
\hline Oxygen saturation ${ }^{\mathrm{e}}(\%)$ & $98(96-99)$ & $94(91-96)$ & $<0.001$ \\
\hline White blood cell count ${ }^{f}\left(\times 10^{9}\right.$ cells per $\left.L\right)$ & $6.4(5.0-7.9)$ & $6.6(5.2-8.6)$ & 0.058 \\
\hline Lymphocyte count ${ }^{9}\left(\times 10^{9}\right.$ cells per $\left.\mathrm{L}\right)$ & $1.7(1.2-2.2)$ & $1.0(0.7-1.3)$ & $<0.001$ \\
\hline Platelet count ${ }^{9}\left(\times 10^{9}\right.$ cells per $\left.\mathrm{L}\right)$ & $235(189-283)$ & $202.5(171.5-242.5)$ & $<0.001$ \\
\hline Serum sodium ${ }^{h}(\mathrm{mmol} / \mathrm{L})$ & $138(136-140)$ & $135(133-137)$ & $<0.001$ \\
\hline Serum creatinine $(\mu \mathrm{mol} / \mathrm{L})$ & $80(68-90)$ & $90(76.5-108.5)$ & $<0.001$ \\
\hline $\mathrm{CRP}^{\mathrm{j}}(\mathrm{mg} / \mathrm{L})$ & $7.0(5-33.8)$ & $107.7(55.3-169.5)$ & $<0.001$ \\
\hline $\operatorname{ALT}^{\mathrm{k}}(\mathrm{U} / \mathrm{L})$ & $27(19-40)$ & $32(21.5-50.5)$ & $<0.001$ \\
\hline Chest radiology showing pulmonary infiltrates & $457 / 1275(35.8 \%)$ & $102(94.4 \%)$ & $<0.001$ \\
\hline \multicolumn{4}{|l|}{ Management } \\
\hline Highest respiratory support in the first $24 \mathrm{~h}$ of hospitalization & & & $<0.001$ \\
\hline Ambient air & $1226(94.2 \%)$ & $7(6.5 \%)$ & \\
\hline Oxygen via face mask or nasal canulae & $75(5.8 \%)$ & $45(41.7 \%)$ & \\
\hline Non-invasive mechanical ventilation & 0 & $14(13 \%)$ & \\
\hline Invasive mechanical ventilation & 0 & $42(38.9 \%)$ & \\
\hline Invasive mechanical ventilation anytime during hospitalization & 0 & $91(84.3 \%)$ & $<0.001$ \\
\hline Vasopressor support & $2(0.2 \%)$ & $66(61.1 \%)$ & $<0.001$ \\
\hline Renal replacement therapy & $4(0.3 \%)$ & $16(14.8 \%)$ & $<0.001$ \\
\hline \multicolumn{4}{|l|}{ Antiviral and Anti-inflammatory Therapy } \\
\hline Hydroxychloroquine & $936(71.9 \%)$ & $108(100.0 \%)$ & $<0.001$ \\
\hline Azithromycin & $791(60.8 \%)$ & $107(99.1 \%)$ & $<0.001$ \\
\hline Lopinavir-ritonavir & $435(33.4 \%)$ & $87(80.6 \%)$ & $<0.001$ \\
\hline Ribavirin & $33(2.5 \%)$ & $74(68.5 \%)$ & $<0.001$ \\
\hline Interferon & $1(0.1 \%)$ & $26(24.1 \%)$ & $<0.001$ \\
\hline Tocilizumab & $12(0.9 \%)$ & $99(91.7 \%)$ & $<0.001$ \\
\hline Systemic corticosteroids & $7(0.5 \%)$ & $71(65.7 \%)$ & $<0.001$ \\
\hline \multicolumn{4}{|l|}{ Complications } \\
\hline Acute respiratory distress syndrome & 0 & $94(87 \%)$ & $<0.001$ \\
\hline Acute kidney injury & $20(1.5 \%)$ & $47(43.5 \%)$ & $<0.001$ \\
\hline Myocardial injury & $4(0.3 \%)$ & $16(14.8 \%)$ & $<0.001$ \\
\hline Thromboembolism & 0 & $3(2.8 \%)$ & $<0.001$ \\
\hline Arrhythmia & 0 & $4(3.7 \%)$ & $<0.001$ \\
\hline \multicolumn{4}{|l|}{ Length of stay (days) } \\
\hline Hospital length of stay & $7(3-12)$ & $24.5(19-37.5)$ & $<0.001$ \\
\hline ICU length of stay & NA & $12(8-21)$ & NA \\
\hline
\end{tabular}

Data are median (IQR), $\mathrm{n}(\%)$, or $\mathrm{n} / \mathrm{N}(\%)$, where $\mathrm{N}$ is the total number of patients with available data. $P$ values comparing ICU and non-ICU are from Pearson's chisquared test, Fisher's exact test, or Wilcoxon rank-sum test. ${ }^{a}$ Data missing for 246 (17.5\%). ${ }^{b}$ Data missing for $16,(1.1 \%)$. ${ }^{\circ}$ Data missing for 179 (12.7\%). ${ }^{d}$ Data

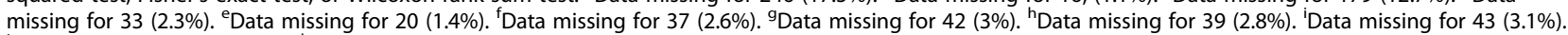
'Data missing for 148 (10.5\%). " Data missing for 83 (5.9\%). ALT Alanine transaminase; CRP C-reactive protein; ICU Intensive care unit; NA Not applicable; WHO World Health Organization

several possible explanations for our findings. Firstly, as of July 11, 2020, the total number of SARS-CoV-2 RTPCR tests performed in Qatar is 142 per 1000 population, compared with 97.6 in Italy, 117.6 in the United States, and 102.8 in the United Kingdom [15]. Higher
COVID-19-associated mortality rates are often reported from settings where COVID-19 testing is not readily available for those who do not have severe symptoms, thus skewing outcome assessments towards the severe end of the COVID-19's clinical spectrum [2-4, 7]. On 
Table 2 Risk factors associated with admission of COVID-19 patients to ICU

\begin{tabular}{|c|c|c|}
\hline Variable & Univariable OR ( $95 \% \mathrm{Cl}, P$ value) & Multivariable OR ( $95 \% \mathrm{Cl}, P$ value) \\
\hline Age (per year increase) & $1.056(1.041-1.071, P<0.001)$ & $1.041(1.022-1.061, P<0.001)$ \\
\hline Male sex (versus female) & $2.741(1.316-5.711$, P 0.007$)$ & $4.375(1.964-9.744, P<0.001)$ \\
\hline \multicolumn{3}{|l|}{ Co-morbidity present (versus not present) } \\
\hline Diabetes mellitus & $3.461(2.319-5.164, P<0.001)$ & $1.698(1.050-2.746$, P 0.031$)$ \\
\hline Hypertension & $2.919(1.941-4.340, P<0.001)$ & $0.980(0.589-1.630$, P 0.937$)$ \\
\hline Coronary artery disease & $4.180(1.991-8.778, P<0.001)$ & $1.090(0.449-2.643$, P 0.849$)$ \\
\hline Chronic lung disease & $1.717(0.859-3.430$, P 0.126$)$ &.. \\
\hline Chronic liver disease & $3.536(1.143-10.934$, P 0.028$)$ & $2.463(0.716-8.465$, P 0.153$)$ \\
\hline Chronic kidney disease & $8.341(4.050-17.177, P<0.001)$ & $3.590(1.596-8.079$, P 0.002) \\
\hline BMI (per one $\mathrm{kg} / \mathrm{m}^{2}$ increase) & $1.067(1.033-1.102, P<0.001)$ & $1.067(1.027-1.108$, P 0.001$)$ \\
\hline \multicolumn{3}{|l|}{ Presenting symptoms (versus not present) } \\
\hline Fever & $28.542(9.011-90.401, P<0.001)$ & \\
\hline Cough & $6.145(3.339-11.312, P<0.001)$ & \\
\hline Dyspnea & $7.879(5.123-11.909, P<0.001)$ & \\
\hline Sore throat & $0.660(0.403-1.079, P<0.001)$ & \\
\hline Rhinorrhea & $0.833(0.0115-0.602$, P 0.014$)$ & \\
\hline \multicolumn{3}{|l|}{ Baseline vital signa (per unit increase) } \\
\hline Systolic blood pressure $(\mathrm{mmHg})$ & 0.987 (0.973-1.001, P 0.062) & \\
\hline Heart rate (beats per minute) & $1.037(1.024-1.049, P<0.001)$ & \\
\hline Respiratory rate (breaths per minute) & $1.264(1.217-1.313, P<0.001)$ & \\
\hline Oxygen saturation (\%) & $0.651(0.605-0.701, P<0.001)$ & \\
\hline \multicolumn{3}{|c|}{ Baseline laboratory results (per unit increase) } \\
\hline Lymphocytes count ( $\times 10^{9}$ per $\left.\mathrm{L}\right)$ & $0.155(0.100-0.240, P<0.001)$ & \\
\hline Platelet count $\left(\times 10^{9}\right.$ per $\left.\mathrm{L}\right)$ & $0.993(0.990-0.996, P<0.001)$ & \\
\hline Serum sodium (mmol/L) & $0.801(0.757-0.848, P<0.001)$ & \\
\hline Serum creatinine $(\mu \mathrm{mol} / \mathrm{L})$ & $1.003(1.001-1.005, P<0.005)$ & \\
\hline CRP (mg/L) & $1.016(1.013-1.019, P<0.001)$ & \\
\hline $\operatorname{ALT}(U / L)$ & $1.001(0.999-1.002$, P 0.2) & \\
\hline
\end{tabular}

ALT Alanine transaminase; BMI Body mass index (calculated as weight in kilograms divided by height in meters squared); CI Confidence interval; COVID-19 Coronavirus disease 2019; CRP C-reactive protein; ICU Intensive care unit; IQR Interquartile range.; OR Odds ratio

the other hand, nearly one third of patients reported in our study were identified through screening efforts. Our lower mortality rates could therefore be in part due to higher detection of milder COVID-19 cases.

Secondly, our cohort's demographic profile is consistent with the country's population being largely constituted of male migrants working in the country's numerous infrastructure projects (Table S6, supplement). Older age and the presence of multiple co-morbidities have consistently been associated with increased risk of severe COVID-19, need for critical care support, and mortality $[7,9,16]$. The majority $(83 \%)$ of patients in our study did not have any pre-existing chronic medical conditions. Moreover, with a median patient age of 35 years (IQR 28-43), our patients were considerably younger than those reported in large cohorts from Lombardy Region in Italy (median 63 year, IQR
56-70), the United Kingdom (median 73 years, IQR 58-82 years) and New York City (median 54 years, IQR 38-66) [5-7]. Note should also be taken of Qatar's population being relatively younger than most countries reporting high COVID-19-associated mortality. For example, the median age in Qatar is only 33.2 years, whereas the median population age is 45.5 years in Italy, and 40.5 years in the United Kingdom [17]. In addition, the proportion of population aged over 65 years is only $1.3 \%$ in Qatar, while it is $23 \%$ in Italy and $18.5 \%$ in the United Kingdom [18].

A third factor in explaining our low COVID-19associated mortality is the rapid escalation of the healthcare system's capacity to accommodate the expected hike in demand for hospital beds in general, and for ICU support in particular. It has been suggested that some of the worst COVID-19-associated mortality rates have in 
part been the result of overwhelmed critical care resources that could not support a large influx of severely ill COVID-19 patients [3, 19]. This has stimulated discussions around rationing of critical care support for COVID-19 patients, including potentially difficult decisions to withdraw resources from one patient to provide them to another [20]. On the other hand, critical care support is rarely withheld in our setting, even in cases where the prognosis appears to be unfavorable.

While diabetes mellitus, coronary artery disease, chronic liver disease, hypertension and chronic kidney diseases all appeared to be associated with risk of admission to ICU in our univariate analysis, the association was statistically significant only for the latter wo in the adjusted logistic regression analysis (Table 2). This is probably the result of interactions between our cohort's co-morbidities and their age.

Deaths observed in our study have largely occurred in older patients with multiple co-morbidities. Though $85.7 \%$ of deaths occurred in those aged 55 years or above, this group constituted only $7.4 \%$ of our entire cohort. Our age group-specific mortality was $2.5 \%$ in those aged $55-64$ years, and $5.4 \%$ in those aged 65 years or more. These figures are comparable with mortality rates in similar age groups in China, Italy, and the United States, but are considerably lower than those reported from the United Kingdom [6, 8, 9, 21].

One patient in our cohort died while in a community isolation facility with asymptomatic SARS-CoV-2 infection. His rapid demise after complaining of chest pain suggests that his death was caused by myocardial infarction or pulmonary embolism. Both complications are increasingly recognized associations with COVID-19 [22, 23]. An increase in out-of-hospital cardiac arrests has been observed in association with SARS-CoV-2 pandemic, including in patients with symptoms compatible with COVID-19 [24]. Moreover, $14.8 \%$ of our ICU patients and $0.3 \%$ of our non-ICU patients had evidence of myocardial injury during their hospitalization. The diagnosis of COVID-19 in patients with known or increased risk of coronary artery disease should be an opportunity to review and optimize medical therapy to reduce the risk of acute coronary events.

Most hospitalized patients in our study received investigational antiviral therapies. However, recent reports from large cohort and randomized clinical trials do not support the use of hydroxychloroquine, alone or in combination with azithromycin, or lopinavir-ritonavir for patients with COVID-19 $[25,26]$. It is likely that COVID-19 management will continue to evolve as more results from ongoing clinical trials become available [27].

Our analysis showed that increasing age, male sex, higher BMI, and the presence of diabetes or chronic kidney disease are risk factors for admission to ICU. Remarkably, hypertension, chronic lung disease, and coronary artery disease, all of which are frequently reported as important predictors for severe COVID-19 in previous studies, were not independently associated with ICU admission in our setting [28]. Furthermore, our univariable analysis showed that presenting with dyspnea and cough as well as baseline blood abnormalities such as lower lymphocyte count, higher CRP and serum creatinine are associated with increased risk of admission to ICU $[28,29]$.

Higher BMI as a risk factor for severe COVID-19 is particularly noteworthy [30]. Median BMI in our hospitalized patients was $26.8 \mathrm{~kg} / \mathrm{m}^{2}$ (IQR 23.9-29.8), a reflection of the growing concern over the increasing prevalence of overweight and obesity in developing countries, along with its consequent health problems such as diabetes and cardiovascular disease [31]. In the context of COVID-19, it is important to recognize the role of overweight and obesity as a driver of severe COVID-19. Our findings help guide deployment of medical resources to better select patients for hospitalization, closer clinical monitoring, and early clinical support.

Healthcare workers represented $2.7 \%$ of cases in our report. Three (2.2\%) of our healthcare workers required admission to ICU. Unlike some unfortunate reports from elsewhere, all healthcare workers in our study fully recovered within the study follow up period [32]. Risk to healthcare personnel is highest in those with prolonged direct contact with symptomatic patients, especially where personal protective equipment are either in short supply or not used appropriately [33]. Also noteworthy is that $28.2 \%$ of healthcare workers in this study were asymptomatic. Single center healthcare worker screening studies reported asymptomatic rates ranging from 12.2 to $34 \%$ [34, 35]. The most efficient healthcare worker screening strategy that combines practicality with patient protection is still unclear.

Like previous reports, children in our study had a largely uneventful SARS-CoV-2 infection [36].

While only $28.5 \%$ of the entire cohort were hospitalized, the majority (73.1\%) of pregnant women with COVID-19 in our report were hospitalized. However, only one (3.8\%) out of 26 pregnant women in this report required admission to ICU, and none died within 60 days of follow up. Our findings are consistent with recent reports indicating that pregnancy may be independently associated with increased risk of hospitalization and severe COVID-19 [37, 38].

The limitations of this study include its observational nature and missing data for some variables. To address those limitations, we used multivariate analyses with 
multiple imputations to assess independent associations with the outcome. Despite this, our study benefits from being, to the best of our knowledge, the first to report 60 -day outcomes of SARS-CoV-2, and to do so at a nationwide level.

\section{Conclusions}

In a setting of proactive SARS-CoV-2 case finding, a younger population, and low co-morbidity burden, SARS-CoV-2 was associated with low all-cause mortality. Independent risk factors for ICU admission included older age, male sex, higher BMI, and co-existing diabetes or chronic kidney disease.

\section{Supplementary information}

Supplementary information accompanies this paper at https://doi.org/10. 1186/s12879-020-05511-8.

Additional file 1 Table S1. Baseline characteristics and outcomes of 5000 individuals with Coronavirus Disease 2019 in Qatar. Table S2. Coronavirus Disease 2019-associated deaths in Qatar. Table S3. Pregnant women with Coronavirus Disease 2019 in Qatar. Table S4. Healthcare Workers with Coronavirus Disease 2019 in Qatar. Table S5. Children with Coronavirus Disease 2019 in Qatar. Table S6. Qatar population and corresponding SARS-CoV-2 infection incidence per 100,000 population by sex and age group.

\section{Acknowledgments}

We would like to thank all colleagues in Hamad Medical Corporation and the Ministry of Public Health for their outstanding service and dedication.

\section{Authors' contributions}

Conceptualization, ASO; Data curation, RAA, ME, SHS, TBHI, AZ, DB, AMA, AB, $B A, R E, A A M H, M N B, F B, S H A, S A, A K, K C, V R C, K A, M A, A A H$ and PVC; Formal analysis, ASO, JD and MAS; Methodology, ASO and JD; Resources, MAA, AA and HMA; Writing - original draft, ASO and JD; Writing - review \& editing, $\mathrm{RB}, \mathrm{MPF}, \mathrm{AA}$ and HMA. The author (s) read and approved the final manuscript.

\section{Funding}

The publication of this article was supported by the Medical Research Center, Hamad Medical Corporation. No other funding was required.

\section{Availability of data and materials}

The datasets used and analyzed during the current study are available from the corresponding author on reasonable request.

\section{Ethics approval and consent to participate}

The study was approved by Hamad Medical Corporation's Institutional Review Board (MRC0120191), with a waiver of informed consent. No additional administrative permissions were required to access the raw data. All data used in this study were anonymized before their use.

\section{Consent for publication}

Not applicable.

\section{Competing interests}

The authors declare that they have no competing interests.

\section{Author details}

${ }^{1}$ Communicable Diseases Center, Hamad Medical Corporation, Doha, QatarPO Box 3050. ${ }^{2}$ Medical Education Center, Hamad Medical Corporation, Doha, QatarPO Box 3050. ${ }^{3}$ Division of Critical Care, Department of Medicine, Hamad Medical Corporation, Doha, QatarPO Box 3050. ${ }^{4}$ Hazm Mebaireek General Hospital, Hamad Medical Corporation, Doha, Qatar. ${ }^{5}$ Hamad General
Hospital, Hamad Medical Corporation, Doha, QatarPO Box 3050. 'usiness Intelligence Unit, Hamad Medical Corporation, Doha, QatarPO Box 3050.

${ }^{7}$ Rumailah Hospital, Hamad Medical Corporation, Doha, QatarPO Box 3050.

${ }^{8}$ Division of Virology, Hamad Medical Corporation, Doha, QatarPO Box 3050.

${ }^{9}$ Ministry of Public Health, Doha, QatarPO Box 42. ${ }^{10}$ Scientific, Academic and Faculty Affairs, Hamad Medical Corporation, Doha, QatarPO Box 3050.

Received: 14 July 2020 Accepted: 12 October 2020

Published online: 19 October 2020

\section{References}

1. World Health Organization. Coronavirus disease 2019 (COVID-19) Situation report - 174. https://www.who.int/docs/default-source/coronaviruse/ situation-reports/20200712-covid-19-sitrep-174.pdf?sfvrsn=5d1c1b2c_2 (accessed July 13, 2020).

2. Baud D, Qi X, Nielsen-Saines K, Musso D, Pomar L, Favre G. Real estimates of mortality following COVID-19 infection. Lancet Infect Dis. 2020;20(7):773. https://doi.org/10.1016/S1473-3099(20)30195-XI.

3. Boccia S, Ricciardi W, loannidis JPA. What other countries can learn from Italy during the COVID-19 pandemic. JAMA Intern Med. 2020;180(7):927-8. https://doi.org/10.1001/jamainternmed.2020.14471.

4. Public Health England. COVID-19: investigation and initial clinical management of possible cases. https://www.gov.uk/government/ publications/wuhan-novel-coronavirus-initial-investigation-of-possible-cases/ investigation-and-initial-clinical-management-of-possible-cases-of-wuhannovel-coronavirus-wn-cov-infection\#interim-definition-possible-cases (accessed July 13, 2020)

5. Grasselli G, Zangrillo A, Zanella A, Antonelli M, Cabrini L, Castelli A, et al. Baseline characteristics and outcomes of 1591 patients infected with SARSCoV-2 admitted to ICUs of the Lombardy region, Italy. JAMA. 2020;323(16): 1574-81. https://doi.org/10.1001/jama.2020.53941.

6. Docherty $A B$, Harrison EM, Green CA, Hardwick HE, Pius R, Norman L, et al. Features of 20133 UK patients in hospital with COVID-19 using the ISARIC WHO clinical characterisation protocol: prospective observational cohort study. BMJ. 2020;369:m1985. https://doi.org/10. 1136/bmj.m1985l.

7. Petrilli CM, Jones SA, Yang J, Rajagopalan H, O'Donnell L, Chernyak $Y$, et al. Factors associated with hospital admission and critical illness among 5279 people with coronavirus disease 2019 in New York City: prospective cohort study. BMJ. 2020;369:m1966. https://doi.org/10.1136/ bmj.m1966l.

8. Chinese Center for Disease Control and Prevention. Vital surveillances: the epidemiological characteristics of an outbreak of 2019 novel coronavirus diseases (COVID-19) - China, 2020. China CDC Wkly. 2020;2(8):113-22. https://doi.org/10.46234/ccdcw2020.0321.

9. CDC COVID-19 Response Team. Severe outcomes among patients with coronavirus disease 2019 (COVID-19) - United States, February 12-March 16, 2020. MMWR Morb Mortal Wkly Rep. 2020;69(12):343-6. https://doi.org/10. 15585/mmwr.mm6912e2l.

10. Marshall JC, Murthy S, Diaz J, Adhikari NK, Angus DC, Arabi YM, et al. A minimal common outcome measure set for COVID-19 clinical research. Lancet Infect Dis. 2020;20(8):e192-7. https://doi.org/10.1016/s14733099(20)30483-71.

11. World Health Organization. Clinical management of COVID-19 - interim guidance 27 May 2020. https://apps.who.int/iris/rest/bitstreams/1278777/ retrieve (accessed July 13, 2020).

12. Alattar R, Ibrahim TBH, Shaar SH, Abdalla S, Shukri K, Daghfal JN, et al. Tocilizumab for the treatment of severe coronavirus disease 2019. J Med Virol. 2020;92(10):2042-9. https://doi.org/10.1002/jmv.25964l.

13. von Elm E, Altman DG, Egger M, Pocock SJ, Gotzsche PC, Vandenbroucke $J P$, et al. The strengthening the reporting of observational studies in epidemiology (STROBE) statement: guidelines for reporting observational studies. Ann Intern Med. 2007;147(8):573-7. https://doi.org/10.7326/00034819-147-8-200710160-00010l.

14. Borges do Nascimento IJ, Cacic N, Abdulazeem HM, von Groote TC, Jayarajah U, Weerasekara I, et al. Novel coronavirus infection (COVID-19) in humans: a scoping review and meta-analysis. J Clin Med. 2020;9(4):941. https://doi.org/10.3390/jcm9040941l.

15. Our World in Data. Coronavirus (COVID-19) Testing. https://ourworldindata. org/coronavirus-testing (accessed July 13, 2020). 
16. Wu JT, Leung K, Bushman M, Kishore N, Niehus R, de Salazar PM, et al. Estimating clinical severity of COVID-19 from the transmission dynamics in Wuhan, China. Nat Med. 2020;26(4):506-10. https://doi.org/10.1038/s41591020-0822-7l.

17. Wikipedia. List of countries by median age. https://en.wikipedia.org/wiki/ List of countries by median age (accessed July 13, 2020).

18. Wikipedia. List of countries by age structure. https://en.wikipedia.org/wiki/ List_of_countries_by_age_structure (accessed July 13, 2020).

19. Ji Y, Ma Z, Peppelenbosch MP, Pan Q. Potential association between COVID19 mortality and health-care resource availability. Lancet Glob Health. 2020; 8(4):e480. https://doi.org/10.1016/S2214-109X(20)30068-11.

20. White $D B$, Lo B. A framework for rationing ventilators and critical care beds during the COVID-19 pandemic. JAMA. 2020;323(18):1773-4. https://doi.org/ 10.1001/jama.2020.5046l.

21. Onder G, Rezza G, Brusaferro S. Case-fatality rate and characteristics of patients dying in relation to COVID-19 in Italy. JAMA. 2020;323(18):1775-6. https://doi.org/10.1001/jama.2020.46831.

22. Bompard F, Monnier H, Saab I, Tordjman M, Abdoul H, Fournier L, et al. Pulmonary embolism in patients with COVID-19 pneumonia. Eur Respir J. 2020;56(1). https://doi.org/10.1183/13993003.01365-2020l.

23. Shi S, Qin M, Shen B, Cai Y, Liu T, Yang F, et al. Association of Cardiac Injury with Mortality in hospitalized patients with COVID-19 in Wuhan, China. JAMA Cardiol. 2020;5(7):802-10. https://doi.org/10.1001/jamacardio.2020. 0950l.

24. Baldi E, Sechi GM, Mare C, Canevari F, Brancaglione A, Primi R, et al. Out-ofhospital cardiac arrest during the Covid-19 outbreak in Italy. N Engl J Med. 2020;383(5):496-8. https://doi.org/10.1056/NEJMc2010418l.

25. Rosenberg ES, Dufort EM, Udo T, Wilberschied LA, Kumar J, Tesoriero J, et al. Association of treatment with Hydroxychloroquine or azithromycin with inhospital mortality in patients with COVID-19 in New York state. JAMA. 2020; 323(24):2493-502. https://doi.org/10.1001/jama.2020.8630l.

26. Cao B, Wang Y, Wen D, Liu W, Wang J, Fan G, et al. A trial of Lopinavirritonavir in adults hospitalized with severe Covid-19. N Engl J Med. 2020; 382(19):1787-99. https://doi.org/10.1056/NEJMoa2001282l.

27. Lythgoe MP, Middleton P. Ongoing clinical trials for the management of the COVID-19 pandemic. Trends Pharmacol Sci. 2020;41(6):363-82. https:// doi.org/10.1016/j.tips.2020.03.0061.

28. Zheng Z, Peng F, Xu B, Zhao J, Liu H, Peng J, et al. Risk factors of critical \& mortal COVID-19 cases: a systematic literature review and meta-analysis. J Inf Secur. 2020;81(2):e16-25. https://doi.org/10.1016/j.jinf.2020.04.021I.

29. Jain V, Yuan JM. Predictive symptoms and comorbidities for severe COVID19 and intensive care unit admission: a systematic review and meta-analysis. Int J Public Health. 2020;65(5):533-46. https://doi.org/10.1007/s00038-02001390-7l.

30. Simonnet A, Chetboun M, Poissy J, Raverdy V, Noulette J, Duhamel A, et al. High prevalence of obesity in severe acute respiratory syndrome Coronavirus-2 (SARS-CoV-2) requiring invasive mechanical ventilation. Obesity (Silver Spring). 2020;28(7):1195-9. https://doi.org/10.1002/oby.228311.

31. Yoon KH, Lee JH, Kim JW, Cho JH, Choi YH, Ko SH, et al. Epidemic obesity and type 2 diabetes in Asia. Lancet. 2006;368(9548):1681-8. https://doi.org/ 10.1016/S0140-6736(06)69703-11.

32. Lapolla P, Mingoli A, Lee R. Deaths from COVID-19 in healthcare workers in Italy-what can we learn? Infect Control Hosp Epidemiol. 2020:1-2. https:// doi.org/10.1017/ice.2020.2411.

33. Wang J, Zhou M, Liu F. Reasons for healthcare workers becoming infected with novel coronavirus disease 2019 (COVID-19) in China. J Hosp Infect. 2020;105(1):100-1. https://doi.org/10.1016/j.jhin.2020.03.002I.

34. Khalil A, Hill R, Ladhani S, Pattisson K, O'Brien P. COVID-19 screening of health-care workers in a London maternity hospital. Lancet Infect Dis. 2020. https://doi.org/10.1016/S1473-3099(20)30403-5I.

35. Lombardi A, Consonni D, Carugno M, Bozzi G, Mangioni D, Muscatello A, et al. Characteristics of 1573 healthcare workers who underwent nasopharyngeal swab testing for SARS-CoV-2 in Milan, Lombardy, Italy. Clin Microbiol Infect. 2020;26(10):1413.E1419-3. https://doi.org/10.1016/j.cmi. 2020.06.0131.

36. Zimmermann P, Curtis N. COVID-19 in children, pregnancy and neonates: a review of epidemiologic and clinical features. Pediatr Infect Dis J. 2020;39(6): 469-77. https://doi.org/10.1097/INF.0000000000002700l.

37. Collin J, Bystrom E, Carnahan A, Ahrne M. Public Health Agency of Sweden's brief report: pregnant and postpartum women with severe acute respiratory syndrome coronavirus 2 infection in intensive care in Sweden. Acta Obstet Gynecol Scand. 2020;99(7):819-22. https://doi.org/10.1111/aogs.13901l.

38. Ellington S, Strid P, Tong VT, Woodworth K, Galang RR, Zambrano LD, et al. Characteristics of women of reproductive age with laboratory-confirmed SARS-CoV-2 infection by pregnancy status - United States, January 22-June 7, 2020. MMWR Morb Mortal Wkly Rep. 2020;69(25):769-75. https://doi.org/ 10.15585/mmwr.mm6925a1l.

\section{Publisher's Note}

Springer Nature remains neutral with regard to jurisdictional claims in published maps and institutional affiliations.

\section{Ready to submit your research? Choose BMC and benefit from:}

- fast, convenient online submission

- thorough peer review by experienced researchers in your field

- rapid publication on acceptance

- support for research data, including large and complex data types

- gold Open Access which fosters wider collaboration and increased citations

- maximum visibility for your research: over $100 \mathrm{M}$ website views per year

At BMC, research is always in progress.

Learn more biomedcentral.com/submissions 